Case Report

\title{
Leclercia adecarboxylata Cholecystitis with Septic Shock in Immunocompetent Patient
}

\author{
Nooraldin Merza $\left(\mathbb{D},{ }^{1}\right.$ John Lung $\mathbb{D}^{2},{ }^{2}$ Ahmed Taha $\left(\mathbb{D},{ }^{1}\right.$ Ahmed Qasim, \\ Jill Frost, ${ }^{3}$ and Tarek Naguib ${ }^{1}$ \\ ${ }^{1}$ Department of Internal Medicine, Texas Tech University Health Sciences Center, Amarillo, TX, USA \\ ${ }^{2}$ School of Medicine, Texas Tech University Health Sciences Center, Amarillo, TX, USA \\ ${ }^{3}$ School of Pharmacy, Texas Tech University Health Science Center, Amarillo, TX, USA
}

Correspondence should be addressed to Nooraldin Merza; nooraldin.merza@ttuhsc.edu

Received 29 April 2019; Accepted 12 June 2019; Published 4 August 2019

Academic Editor: Mehmet Doganay

Copyright (C) 2019 Nooraldin Merza et al. This is an open access article distributed under the Creative Commons Attribution License, which permits unrestricted use, distribution, and reproduction in any medium, provided the original work is properly cited.

L. adecarboxylata is a Gram-negative rod previously named Escherichia adecarboxylata, isolated as normal flora in the gut of animals including human stool. Most reported cases refer to immunocompromised patients with polymicrobial infections and water environments. Here we present a case of 51-year-old immunocompetent female presented with nausea, vomiting, malaise, and subjective fever for few days. On examination, she was drowsy but arousable and oriented to person, place, time, and situation. Her abdomen was tender globally and more tender in the epigastric area. Vitals showed a temperature of $37^{\circ} \mathrm{C}$, pulse of 110 beats $/ \mathrm{min}$, blood pressure of $75 / 50 \mathrm{mmHg}$, and oxygen saturation of $91 \%$ on room air. An HIV panel and hepatitis panel were negative. Liver and gallbladder ultrasound was performed, revealing multiple nonmobile stones with shadowing noted within the gallbladder sac, a thickened gallbladder wall, and a moderate amount of pericholecystic fluid. Broad spectrum antibiotics, crystalloid fluids, and vasopressors were initiated. A few hours after admission she developed respiratory failure for which she underwent endotracheal intubation. An ultrasound guided gallbladder drain was performed. Culture of the biliary fluid yielded pure growth of pan-sensitive L. adecarboxylata; antibiotics were narrowed accordingly. The patient was on the maximum doses of vasopressin, norepinephrine, and epinephrine with a blood pressure of 75/45 and a mean arterial pressure of 51 . She passed away on the fourth day of admission.

\section{Background}

Leclercia adecarboxylata is a unique Enterobacteriaceae member frequently isolated from water with infrequent case reports in the literature. Originally described by Leclerc in 1962 as Escherichia adecarboxylata, these facultative aerobic, Gram-negative bacilli were reclassified by the development of more accurate identification methods as a member of the Enterobacteriaceae family [1]. This bacterium is usually associated with polymicrobial infection in immunocompromised individuals, although there are recent observations of finding this microorganism in healthy individual. We hereby report a unique case of cholecystitis leading to septic shock caused by Leclercia adecarboxylata in an immunocompetent individual without significant water exposure.

\section{Case Report}

A 51-year-old female presented to the emergency department with nausea, vomiting, malaise, and subjective fever for few days. She reported difficulty with ambulation as well as right hip and back pain for several months, with nonsignificant past medical or surgical history. She denied alcohol, drug, or tobacco use. She also denied any recent travel, sick contacts, or exposure to standing water. On physical examination, she was drowsy but arousable and oriented to person, place, time, and situation. Her abdomen was tender globally and more tender in the epigastric area. Vitals showed a temperature of $37^{\circ} \mathrm{C}$, pulse of 110 beats $/ \mathrm{min}$, blood pressure of $75 / 50 \mathrm{mmHg}$, and oxygen saturation of $91 \%$ on room air. Labs are shown in Table 1. An HIV panel, hepatitis panel, ceruloplasmin, 
TABle 1: The patient's lab on days 1,2,3, and 4 .

\begin{tabular}{|c|c|c|c|c|}
\hline & Day 1 & Day 2 & Day 3 & Day 4 \\
\hline $\begin{array}{l}\text { WBC } \\
(\mathrm{x} 10 \mathrm{e} 3 / \mathrm{mcL})\end{array}$ & 9.1 & 7.6 & 12.1 & 13.8 \\
\hline Neutrophils (x10 $3 / \mathrm{mcL})$ & 6.6 & 5.6 & 10.1 & 12.4 \\
\hline Hemoglobin $(\mathrm{gm} / \mathrm{dL})$ & 11.4 & 8.2 & 8.2 & 7.7 \\
\hline Platelets (x10e3/mcL) & 136 & 114 & 45 & 54 \\
\hline INR & 1.52 & 2.2 & 2.7 & 3.0 \\
\hline Fibrinogen $(\mathrm{mg} / \mathrm{dL})$ & & 172 & 61 & 75 \\
\hline D-Dimer $(\mathrm{mg} / \mathrm{L})$ & $>35$ & $>35$ & $>35$ & $>35$ \\
\hline $\begin{array}{l}\text { LDH } \\
\text { (units/L) }\end{array}$ & $>4000$ & 7898 & 9738 & \\
\hline Troponin (ng/mL) & 0.088 & & & \\
\hline Glucose (mg/dL) & 45 & 71 & 117 & 220 \\
\hline $\mathrm{Na}(\mathrm{mmol} / \mathrm{L})$ & 134 & 144 & 145 & 139 \\
\hline $\mathrm{K}(\mathrm{mmol} / \mathrm{L})$ & 6.9 & 6.4 & 4.5 & 3.9 \\
\hline $\begin{array}{l}\text { BUN } \\
(\mathrm{mg} / \mathrm{dL})\end{array}$ & 73 & 63 & 40 & 14 \\
\hline Creatinine (mg/dL) & 2.4 & 2.4 & 2.1 & 1.2 \\
\hline $\begin{array}{l}\mathrm{CO} 2 \\
(\mathrm{mmol} / \mathrm{L})\end{array}$ & 8 & 4 & 11 & 22 \\
\hline Anion Gap (mmol/L) & 22 & 29 & 30 & 13 \\
\hline Lactate $(\mathrm{mmol} / \mathrm{L})$ & 11.5 & 17.5 & 20 & 10 \\
\hline $\begin{array}{l}\text { AST } \\
\text { (units/L) }\end{array}$ & 1650 & 10623 & 17523 & 5846 \\
\hline $\begin{array}{l}\text { ALT } \\
\text { (units/L) }\end{array}$ & 553 & 1953 & 2561 & 1823 \\
\hline $\begin{array}{l}\text { ALP } \\
\text { (units/L) }\end{array}$ & 260 & 257 & 333 & 409 \\
\hline Bilirubin & 0.98 & 2.1 & 2.6 & 4.8 \\
\hline Albumin & 2.5 & 3 & 2.5 & 2.2 \\
\hline
\end{tabular}

antinuclear (ANA) panel, smooth muscle antibody, anticentromere antibody, antichromatin antibody, anti-DNA antibody, anti-Jo-1 antibody, anti-Scl-70 antibody, anti-SSA antibody, and anti-SSB antibody were all negative. Alpha1 antitrypsin was slightly above normal limits at $204 \mathrm{mg} / \mathrm{dl}$ (reference 90-200). Imaging revealed a normal chest Xray. Electrocardiogram showed sinus tachycardia with no ischemic changes. A CT scan of the abdomen showed a gallbladder wall thickening and multiple gallstones. To exclude cholecystitis, a liver and gallbladder ultrasound. (Figure 1) was performed, revealing multiple nonmobile stones with shadowing noted within the gallbladder sac, a thickened gallbladder wall, and a moderate amount of pericholecystic fluid.

Broad spectrum antibiotics (IV vancomycin and piperacillin/tazobactam), crystalloid fluids, and vasopressors were initiated. A few hours after admission she developed respiratory failure for which she underwent endotracheal intubation. Due to her shock state she was not a candidate for surgery. An ultrasound guided gallbladder drain (Figure 2) was performed. Culture of the biliary fluid yielded pure heavy

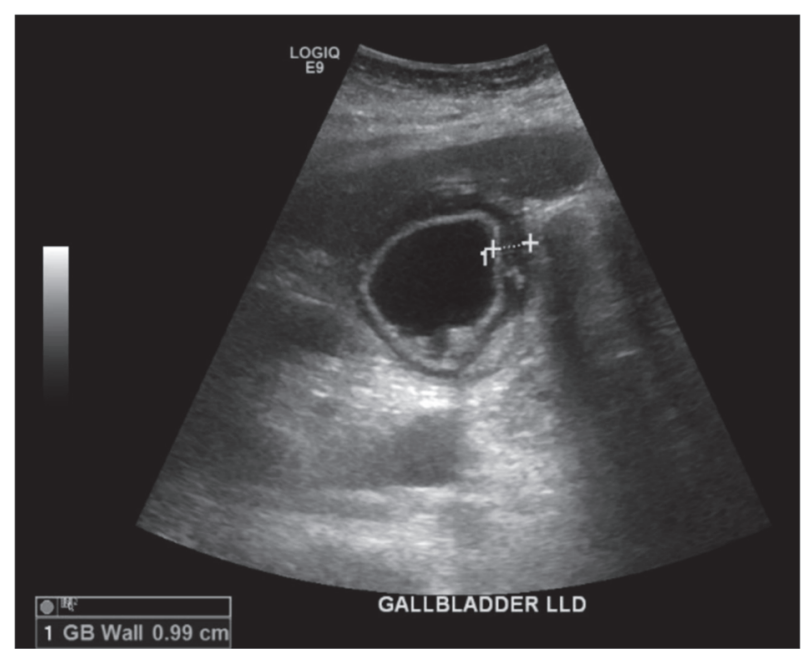

FIGURE 1: Ultrasound of gallbladder showing inflamed gallbladder with multiple nonmobile stones with shadowing in the gallbladder body. The gallbladder wall is thickened to $0.99 \mathrm{~cm}$. A moderate amount of pericholecystic fluid is identified. 


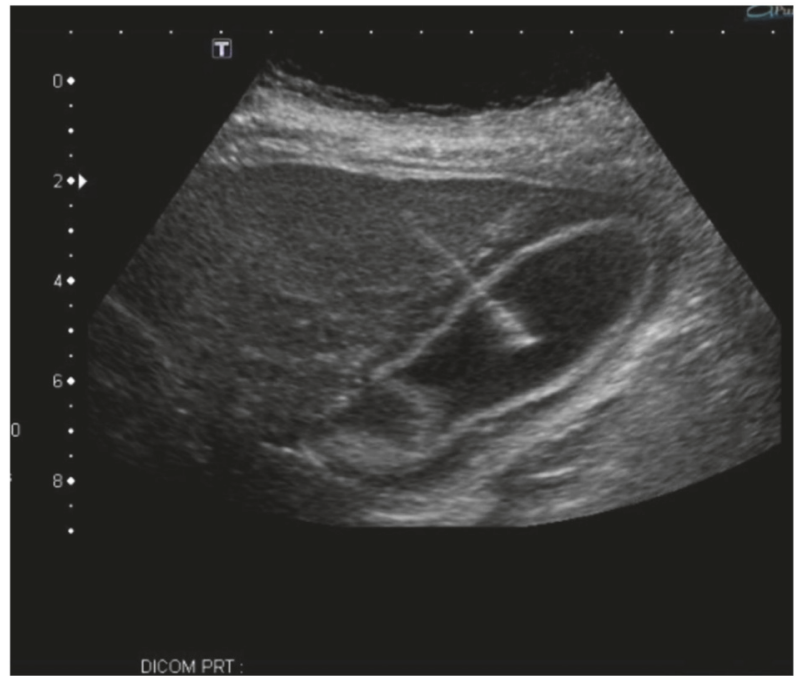

Figure 2: IR-guided cholecystostomy tube placement and drainage and irrigation of the gallbladder with $60 \mathrm{cc}$ of black bile aspiration.

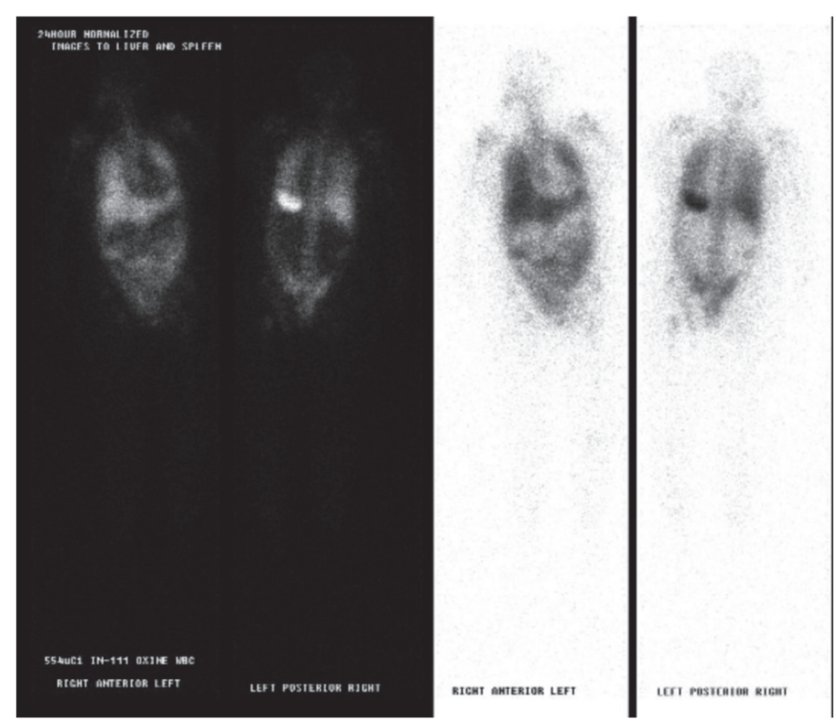

FIGURE 3: Indium-111 white blood cell scan showing no localization of abscess and atypical diffuse pulmonary uptake of white blood cells, which can be associated with an opportunistic infection, pulmonary drug toxicity, and sepsis.

growth of pan-sensitive $L$. adecarboxylata; antibiotics were narrowed accordingly to IV meropenem.

On the second day of admission to the intensive care unit the patient developed signs of disseminated intravascular coagulopathy from septic shock and acute liver failure with profound lactic acidosis and deteriorated rapidly. The patient developed skin mottling of all four extremities due to limb ischemia likely due to peripheral artery vasoconstriction secondary to shock and vasopressor use. The patient had no Doppler signals in the bilateral radial, ulnar, dorsalis pedis, and posterior tibial arteries. Indium-111 tagged WBC scan was performed (Figure 3) to make sure we have not missed another source of infection. This showed diffuse pulmonary uptake which we felt was due to acute respiratory distress syndrome and there was no abscess. The patient received disseminated intravascular coagulation (DIC) treatment including multiple packed red blood cells (PRBC), cryoprecipitate and fresh frozen plasma (FFP) transfusions, and treatment for septic shock including antibiotics and vasopressors.

The patient also received hemodialysis due to acute kidney injury secondary to septic shock. Consults with gastroenterology and general surgery resulted in recommendations of no surgical intervention because of the critical condition of the patient with intubation, mechanical ventilation, hemodialysis, and vasopressors. The patient developed pulseless electrical activity (PEA) cardiac arrest but recovered after one round of cardiopulmonary resuscitation and 1 dose of epinephrine. The patient was on the maximum doses of vasopressin, norepinephrine, and epinephrine with a blood pressure of 75/45 and a mean arterial pressure of 51 .

The patient developed another PEA cardiac arrest 11 hours later and could not be resuscitated despite aggressive resuscitation measures that followed advanced cardiac life support protocol. She passed away on the fourth day of admission.

\section{Discussion}

L. adecarboxylata is a motile, Gram-negative rod previously named Escherichia adecarboxylata, isolated as normal flora in the gut of animals including human stool. Most reported cases refer to immunocompromised patients which gives a clear suggestion of the exclusivity of $L$. adecarboxylata as an opportunistic pathogen associated with polymicrobial infections and water environments, particularly as a contaminant in polluted water $[2,3]$. The paucity of published case reports of human infections with this bacteria may reflect misdiagnosis, as the organism shares many biochemical features with $E$. coli, rather than a true infrequency of human infection [4]. L. adecarboxylata causes infections at various organs including pharyngeal abscess, pneumonia, cholecystitis, gluteal abscess, and cellulitis.

There are at least 74 cases reported in English-language journals since the first case report of $L$. adecarboxylata in 1991, including 19 cases in immunocompetent patients and two cases in patients with cholecystitis, one chronic and one acute (Tables 2 and 3) [2, 4-22].

There is one case in the literature of an 81-year-old female (Table 3) with a past medical history of metabolic syndrome and chronic atrial fibrillation who presented with acute cholecystitis and had a positive L. adecarboxylata biliary fluid culture [10]. The patient in that case report had risk factors for a compromised immune system including old age, cardiovascular risk factors, and metabolic syndrome, while our patient was immunocompetent and did not have any known source for contracting L. adecarboxylata. Our patient tested negative for HIV and hepatitis $\mathrm{B}$ and $\mathrm{C}$ virus. The team ordered a tagged WBC scan to make sure we are not missing another hidden infection.

L. adecarboxylata is not commonly associated with sepsis and rapid deterioration requiring mechanical ventilation and 
TABLE 2: Clinical case reports of $L$. adecarboxylata infections in immunocompetent patients.

\begin{tabular}{|c|c|c|c|c|c|c|}
\hline Case & Age & Gender & $\begin{array}{c}\text { Infection site and } \\
\text { clinical information }\end{array}$ & Co-infection & Outcome & $\begin{array}{c}\text { Identification } \\
\text { method }\end{array}$ \\
\hline $\begin{array}{l}\text { Temesgen et al. } \\
1997\end{array}$ & 35 & M & $\begin{array}{l}\text { right foot would culture, } \\
\text { s/p crush injury }\end{array}$ & $\begin{array}{c}\text { Enterobacter cloacae, } \\
\text { Citrobacter freundii, } \\
\text { Enterococcus species, } \\
\text { Klebsiella pneumoniae, } \\
\text { Stenotrophomonas } \\
\text { maltophilia, and } \\
\text { Corynebacterium, } \\
\text { Acremonium, } \\
\text { Penicillium, Mucor, } \\
\text { Geotrichum } \\
\end{array}$ & Recovery & $\begin{array}{l}\text { Biochemical } \\
\text { testing }\end{array}$ \\
\hline $\begin{array}{l}\text { Temesgen et al. } \\
1997\end{array}$ & 23 & M & $\begin{array}{l}\text { left toe wound culture, } \\
\text { s/p nail puncture }\end{array}$ & $\begin{array}{l}\text { Acinetobacter } \\
\text { calcoaceticus, } \\
\text { Enterobacter } \\
\text { agglomerans }\end{array}$ & Recovery & $\begin{array}{l}\text { Biochemical } \\
\text { testing }\end{array}$ \\
\hline Greco et al. 2001 & 75 & M & $\begin{array}{l}\text { wound culture in right } \\
\text { hand }\end{array}$ & $\begin{array}{c}\text { Staphylococcus } \\
\text { epidermidis }\end{array}$ & Recovery & Not mentioned \\
\hline $\begin{array}{l}\text { Pérez-Moreno et } \\
\text { al. } 2003 \\
\end{array}$ & 60 & M & $\begin{array}{c}\text { synovial fluid, infection } \\
\text { arthritis } \\
\end{array}$ & None & Recovery & $\begin{array}{c}\text { Biochemical } \\
\text { testing }\end{array}$ \\
\hline Hess et al. 2008 & 40 & $\mathrm{~F}$ & $\begin{array}{l}\text { right foot wound culture, } \\
\text { s/p superficial incision } \\
\text { and swimming in pool }\end{array}$ & None & Recovery & $\begin{array}{l}\text { Biochemical } \\
\text { testing }\end{array}$ \\
\hline $\begin{array}{l}\text { Dalamaga et al. } \\
2009\end{array}$ & 53 & M & $\begin{array}{c}\text { left arm wound culture, } \\
\text { s/p chemical injury }\end{array}$ & None & Recovery & $\begin{array}{c}\text { Biochemical } \\
\text { testing }\end{array}$ \\
\hline $\begin{array}{l}\text { Mbamalu and } \\
\text { Macariola } 2011 \\
\end{array}$ & $\begin{array}{c}11 \\
\text { mo }\end{array}$ & M & blood bacteremia & None & & Not mentioned \\
\hline Bali et al. 2013 & 32 & M & $\begin{array}{c}\text { peritonsillar and lateral } \\
\text { pharyngeal abscess }\end{array}$ & None & Recovery & Not mentioned \\
\hline Zapor et al. 2013 & 25 & M & $\begin{array}{l}\text { pus and necrotic tissue } \\
\text { in right buttock, s/p } \\
\text { wartime IED explosion }\end{array}$ & None & Recovery & $\begin{array}{c}\text { 16s ribosomal } \\
\text { sequencing with } \\
\text { 16s rRNA gene } \\
\end{array}$ \\
\hline Haji et al. 2014 & 70 & M & $\begin{array}{c}\text { blood culture, infectious } \\
\text { arthritis }\end{array}$ & None & Recovery & Not mentioned \\
\hline Keren et al. 2014 & 46 & M & $\begin{array}{c}\text { left foot soft tissue } \\
\text { infection, s/p laceration } \\
\text { while surfing }\end{array}$ & Enterobacter cloacae & $\begin{array}{c}\text { Recovery after } 2 \\
\text { weeks }\end{array}$ & $\begin{array}{c}\text { VITEK-2 } \\
\text { automated } \\
\text { microbial- } \\
\text { identification } \\
\text { system } \\
\end{array}$ \\
\hline Anuradha 2014 & 50 & M & gluteal abscess & None & Recovery & $\begin{array}{c}\text { MicroScan } \\
\text { autoSCAN-4 } \\
\text { automated } \\
\text { microbial } \\
\text { identification } \\
\text { system } \\
\end{array}$ \\
\hline Anuradha 2014 & 31 & $\mathrm{~F}$ & vaginal swab, vaginitis & None & $\begin{array}{c}\text { Recovery after } 10 \\
\text { days }\end{array}$ & $\begin{array}{c}\text { MicroScan } \\
\text { autoSCAN-4 } \\
\text { automated } \\
\text { microbial } \\
\text { identification } \\
\text { system } \\
\end{array}$ \\
\hline $\begin{array}{l}\text { Grantham et al. } \\
2015\end{array}$ & 9 & $\mathrm{~F}$ & $\begin{array}{c}\text { left lower extremity soft } \\
\text { tissue infection s/p } \\
\text { penetrating injury }\end{array}$ & None & $\begin{array}{l}\text { Recovery after } 2 \\
\text { months }\end{array}$ & Not mentioned \\
\hline
\end{tabular}


TABLE 2: Continued.

\begin{tabular}{|c|c|c|c|c|c|c|}
\hline Case & Age & Gender & $\begin{array}{l}\text { Infection site and } \\
\text { clinical information }\end{array}$ & Co-infection & Outcome & $\begin{array}{l}\text { Identification } \\
\text { method }\end{array}$ \\
\hline Hurley et al. 2015 & 2 & M & $\begin{array}{l}\text { right thumb soft tissue } \\
\text { infection } \mathrm{s} / \mathrm{p} \text { laceration }\end{array}$ & None & Recovery & $\begin{array}{c}\text { VITEK automated } \\
\text { microbial } \\
\text { identification } \\
\text { system } \\
\end{array}$ \\
\hline Prakash et al. 2015 & 32 & $\mathrm{~F}$ & $\begin{array}{l}\text { tracheal aspirate, } \\
\text { hospital-acquired } \\
\text { pneumonia }\end{array}$ & None & $\begin{array}{l}\text { Recovery after } 1 \\
\text { week }\end{array}$ & $\begin{array}{l}\text { VITEK automated } \\
\text { microbial } \\
\text { identification } \\
\text { system } \\
\end{array}$ \\
\hline Allawh, Camp 2015 & 26 & $\mathrm{~F}$ & $\begin{array}{c}\text { fingernail soft tissue } \\
\text { infection s/p trauma to } \\
\text { nail }\end{array}$ & Staphylococcus & $\begin{array}{l}\text { Not symptomatic } \\
\text { after } 2 \text { weeks }\end{array}$ & Not mentioned \\
\hline Riazzo et al. 2017 & 30 & M & $\begin{array}{l}\text { Subcutaneous trauma } \\
\text { injury to foot }\end{array}$ & $\begin{array}{l}\text { Klebsiella pneumoniae, } \\
\text { Pseudomonas }\end{array}$ & $\begin{array}{c}\text { Discharge after } 3 \\
\text { months }\end{array}$ & $\begin{array}{l}\text { Microscan } \\
\text { Walkaway, } \\
\text { confirmed by } \\
\text { MALDI-TOF }\end{array}$ \\
\hline Capretta et al. 2018 & 9 & M & $\begin{array}{c}\text { right leg soft issue } \\
\text { infection, cellulitis s/p } \\
\text { fall }\end{array}$ & N/A & $\begin{array}{c}\text { Recovery after } 3 \\
\text { weeks }\end{array}$ & Not mentioned \\
\hline
\end{tabular}

TABLE 3: Clinical case reports of L. adecarboxylata infections in patients with cholecystitis who were also immunocompromised.

\begin{tabular}{lccccc}
\hline Case & Age & Gender & Infection site and clinical information & Co-infection & Outcome \\
\hline de Baere et al. 2001 & 78 & F & Chronic cholecystitis & Enterococcus & Recovery \\
\hline Jover-Sáenz et al. 2008 & 81 & F & bile, cholecystitis & None & Recovery after 1 month \\
\hline
\end{tabular}

resuscitative measures as in this case scenario. There is one case report of a patient who developed L. adecarboxylata sepsis, required intubation, and then died in the hospital. This patient had a viral infection prior to admission and then developed pneumonia due to a multidrug-resistant L. adecarboxylata infection [23]. Our patient who developed septic shock had a $L$. adecarboxylata infection was pan-sensitive to most of the tested antibiotics, with no immunocompromising risk factors. Most L. adecarboxylata infections are sensitive to many antibiotic options and frequently respond to treatment without needing to switch antibiotics [24].

Most of L. adecarboxylata strains are naturally sensitive to tetracyclines, aminoglycosides, all but two $\beta$ lactams, quinolones, folate pathway inhibitors, chloramphenicol, nitrofurantoin, and azithromycin. They are naturally resistant to penicillin G, oxacillin, erythromycin, roxithromycin, clarithromycin, ketolides, lincosamides, streptogramins, linezolid, glycopeptides, rifampicin, fusidic acid, and fosfomycin, with only minor medium-dependent differences in susceptibility to most antibiotics $[24,25]$.

However, multiantibiotic resistant L. adecarboxylata has been reported in the literature $[21,26]$, illustrating the need to continue to practice good antibiotic stewardship to prevent development of resistant strains.

The uniqueness of this case could be summarized by the presentation of septic shock with $L$. adecarboxylata in an immunocompetent state. There are only a few reported cases of $L$. adecarboxylata infection in immunocompetent patients [5]. Because L. adecarboxylata is typically found in polymicrobial infections, it is rare to encounter the growth of pure cultures as in this case. There are few reported cases of pure cultures in immunocompetent patients, but not with this severity $[5,22]$. L. adecarboxylata cases in immunocompetent patients are associated with exposed wound infections and contact with water environments [2], while our patient did not have any open wound and lived in a dry, flat area with no open water sources.

\section{Conclusion}

L. adecarboxylata is a rare Gram-negative rod which often infects immunocompromised hosts. We report a case of acute cholecystitis caused by $L$. adecarboxylata leading to profound septic shock with DIC and liver failure that did not respond to aggressive treatment measures. Our case illustrates an opposite picture of what has long been known as an opportunistic organism and a cause of mild infections. We hope by presenting this case we contribute to the current knowledge about this organism and perhaps increase the reporting and identification of the organism as a potential invasive pathogen.

\section{Conflicts of Interest}

The authors declare that there are no conflicts of interest regarding the publication of this paper.

\section{References}

[1] A. Shah, J. Nguyen, L. M. Sullivan, K. R. Chikwava, A. C. Yan, and J. R. Treat, "Leclercia Adecarboxylata cellulitis in a child with 
acute lymphoblastic leukemia," Pediatric Dermatology, vol. 28, no. 2, pp. 162-164, 2011.

[2] Y. Keren, D. Keshet, M. Eidelman, Y. Geffen, A. Raz-Pasteur, and K. Hussein, "Is leclercia adecarboxylata a new and unfamiliar marine pathogen?” Journal of Clinical Microbiology, vol. 52, no. 5, pp. 1775-1776, 2014.

[3] V. Tam and S. Nayak, "Isolation of Leclercia adecarboxylata from a wound infection after exposure to hurricane-related floodwater," BMJ Case Reports, vol. 2012, Article ID 007298, 2012.

[4] B. Hess, A. Burchett, and M. K. Huntington, "Leclercia adecarboxylata in an immunocompetent patient," Journal of Medical Microbiology, vol. 57, no. 7, pp. 896-898, 2008.

[5] M. R. Spiegelhauer, P. F. Andersen, T. H. Frandsen, R. L. M. Nordestgaard, and L. P. Andersen, "Leclercia adecarboxylata: a case report and literature review of 74 cases demonstrating its pathogenicity in immunocompromised patients," Infectious Diseases, pp. 1-10, 2018.

[6] Z. Temesgen, D. R. Toal, and F. R. Cockerill, "Leclercia adecarboxylata infections: case report and review," Clinical Infectious Diseases, vol. 25, no. 1, pp. 79-81, 1997.

[7] T. D. Baere, G. Wauters, A. Huylenbroeck et al., "Isolations of leclercia adecarboxylata from a patient with a chronically inflamed gallbladder and from a patient with sepsis without focus," Journal of Clinical Microbiology, vol. 39, no. 4, pp. 16741675, 2001.

[8] G. Greco, N. Ostojich, Y. Flores, M. Sanchez, L. Clara, and A. Ascione, "Leclercia adecarboxylata, a new enterobacteriaceae in antique infections," Clinical Infectious Diseases, vol. 33, pp. 10871277, 2001.

[9] M. O. Pérez-Moreno, J. Anguera, M. Carulla, and M. PérezMoreno, "Septic arthritis due to Leclercia adecarboxylata of probable iatrogenic origin," Enfermedades Infecciosas y Microbiología Clínica, vol. 21, no. 3, p. 167, 2003.

[10] A. Jover-Sáenz, E. Cerezo-Esforzado, F. Barcenilla-Gaite, S. Garrido-Calvo, and J. M. Porcel-Pérez, "Leclercia adecarboxylata cholecystitis in a patient with metabolic syndrome," Surgical Infections, vol. 9, no. 3, pp. 411-412, 2008.

[11] M. Dalamaga, M. Pantelaki, K. Karmaniolas, K. Daskalopoulou, and I. Migdalis, "Isolation of Leclercia adecarboxylata from blood and burn wound after a hydrofluoric acid chemical injury," Burns, vol. 35, no. 3, pp. 443-445, 2008.

[12] M. Mbamalu and D. Macariola, "Leclercia adecarboxylata sepsis in an immunocompetent pediatric patient," Journal of Investigative Medicine, vol. 59, p. 435, 2011.

[13] R. Bali, P. Sharma, K. Gupta, and S. Nagrath, "Pharyngeal and peritonsillar abscess due to Leclercia adecarboxylata in an immunocompetant patient," The Journal of Infection in Developing Countries, vol. 7, no. 1, p. 46, 2013.

[14] M. Zapor, P. T. McGann, O. Alao, L. Stevenson, E. Lesho, and H. Viscount, "Isolation of leclercia adecarboxylata from an infected war wound in an immune competent patient," Military Medicine, vol. 178, no. 3, pp. e390-e393, 2013.

[15] S. Haji, H. Kimura, and H. Yamashita, "Arthritis and bacteremia due to leclercia adecarboxylata," Internal Medicine, vol. 53, no. 22, pp. 2659-2659, 2014.

[16] M. Anuradha, "Leclercia adecarboxylata isolation: case reports and review," Journal of Clinical and Diagnostic Research : JCDR, vol. 8, no. 12, pp. DD03-DD04, 2014.
[17] W. J. Grantham, S. S. Funk, and J. G. Schoenecker, "Leclercia adecarboxylata musculoskeletal infection in an immune competent pediatric patient: an emerging pathogen?" Case Reports in Orthopedics, vol. 2015, Article ID 160473, 3 pages, 2015.

[18] E. H. Hurley, E. Cohen, J. A. Katarincic, and R. K. Ohnmacht, "Leclercia adecarboxylata infection in an immunocompetent child," Rhode Island Medical Journal, vol. 98, no. 9, p. 41, 2013.

[19] M. R. Prakash, R. Ravikumar, N. Patra, and B. Indiradevi, "Hospital-acquired pneumonia due to Leclercia adecarboxylata in a neurosurgical centre," Journal of Postgraduate Medicine, vol. 61, no. 2, pp. 123-125, 2015.

[20] R. Allawh and B. J. Camp, "Isolation of leclercia adecarboxylata from a patient with a subungual splinter," Dermatology Online Journal, vol. 21, no. 8, 2015.

[21] C. Riazzo, L. López-Cerero, M. D. Rojo-Martín et al., "First report of NDM-1 producing clinical isolate of Leclercia adecarboxylata in Spain," Diagnostic Microbiology \& Infectious Disease, vol. 88, no. 3, pp. 268-270, 2017.

[22] N. Capretta, J. Pearl, J. Lawrence, and C. Gagliardo, “An immunocompetent pediatric patient with rare leclercia adecarboxylata wound infection," Critical Care Medicine, vol. 46, no. 1, p. 344, 2018.

[23] E. H. Eiland, H. Siddiqui, A. M. Goode, and S. D. Leeth, "Pneumonia due to multidrug-resistant Leclercia adecarboxylata," American Journal of Health-System Pharmacy, vol. 70, no. 11, pp. 940-941, 2013.

[24] I. Stock, S. Burak, and B. Wiedemann, "Natural antimicrobial susceptibility patterns and biochemical profiles of Leclercia adecarboxylata strains," Clinical Microbiology and Infection, vol. 10, no. 8, pp. 724-733, 2004.

[25] M. Çiçek, Ö. Tuncer, A. Biçakçigil, N. C. Gürsoy, B. Otlu, and B. Sancak, "A rarely isolated Gram- negative bacterium in microbiology laboratories: leclercia adecarboxylata," Acta Microbiologica et Immunologica Hungarica, vol. 65, no. 2, pp. 241-244, 2018.

[26] V. García-Fulgueiras, V. Seija, P. Aguerrebere, N. F. Cordeiro, and R. Vignoli, "First report of a clinical isolate of leclercia adecarboxylata harbouring multiple resistance genes in uruguay and review of the literature," Journal of Global Antimicrobial Resistance, vol. 2, no. 2, pp. 77-81, 2014. 


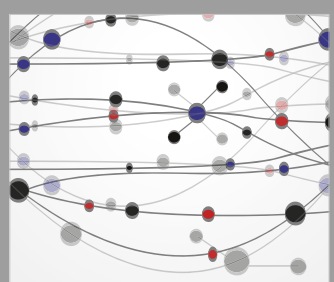

The Scientific World Journal
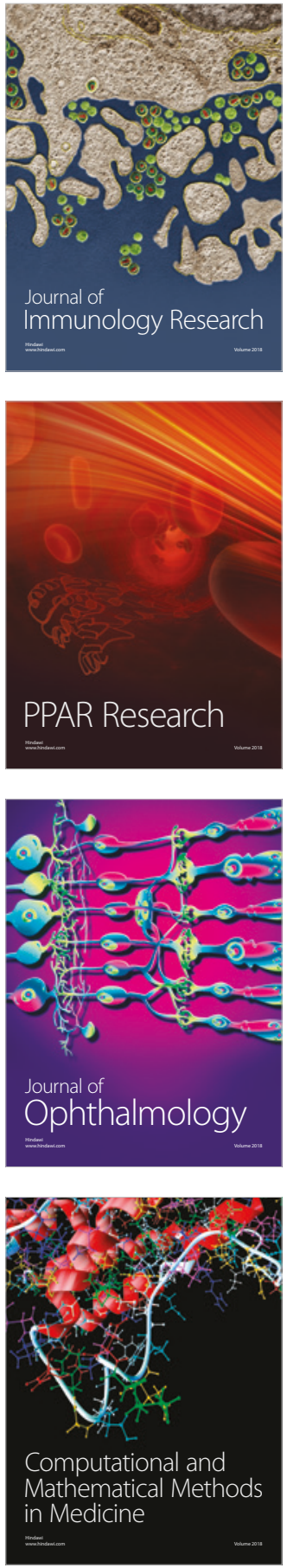

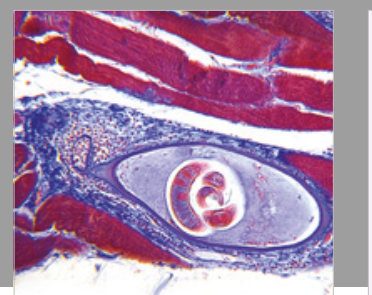

Gastroenterology Research and Practice

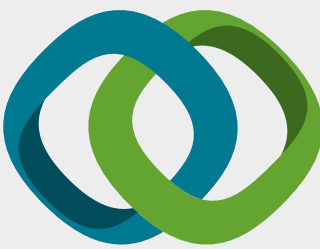

\section{Hindawi}

Submit your manuscripts at

www.hindawi.com
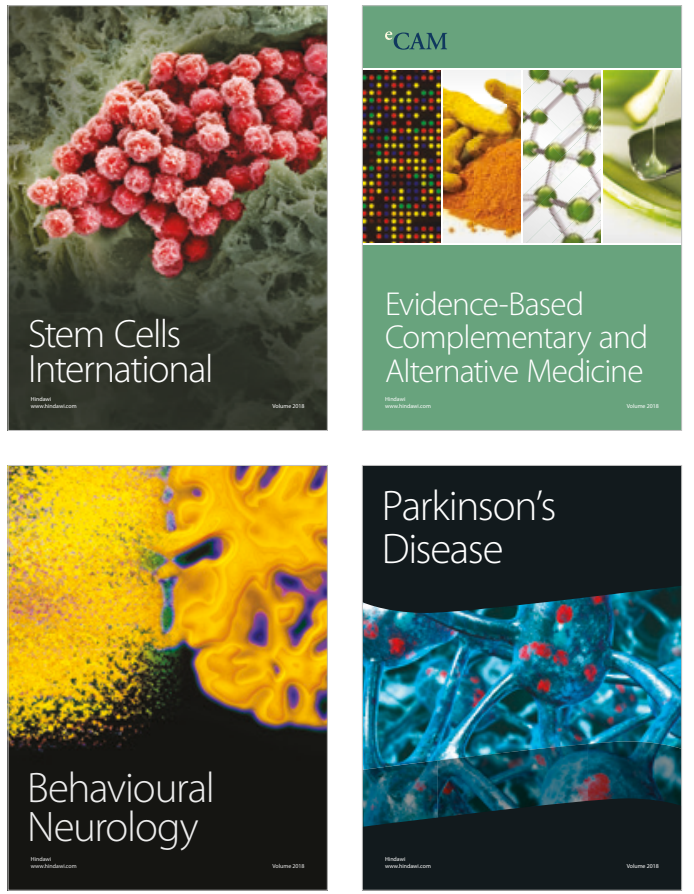

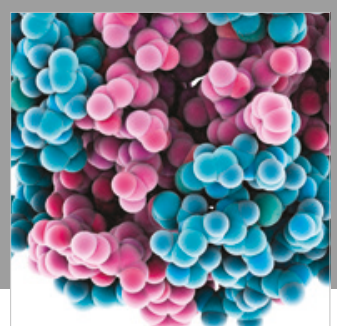

ournal of

Diabetes Research

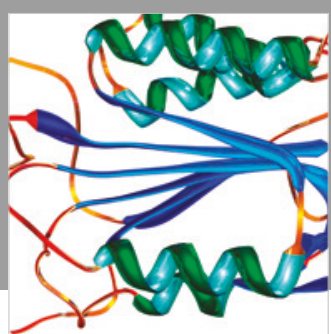

Disease Markers
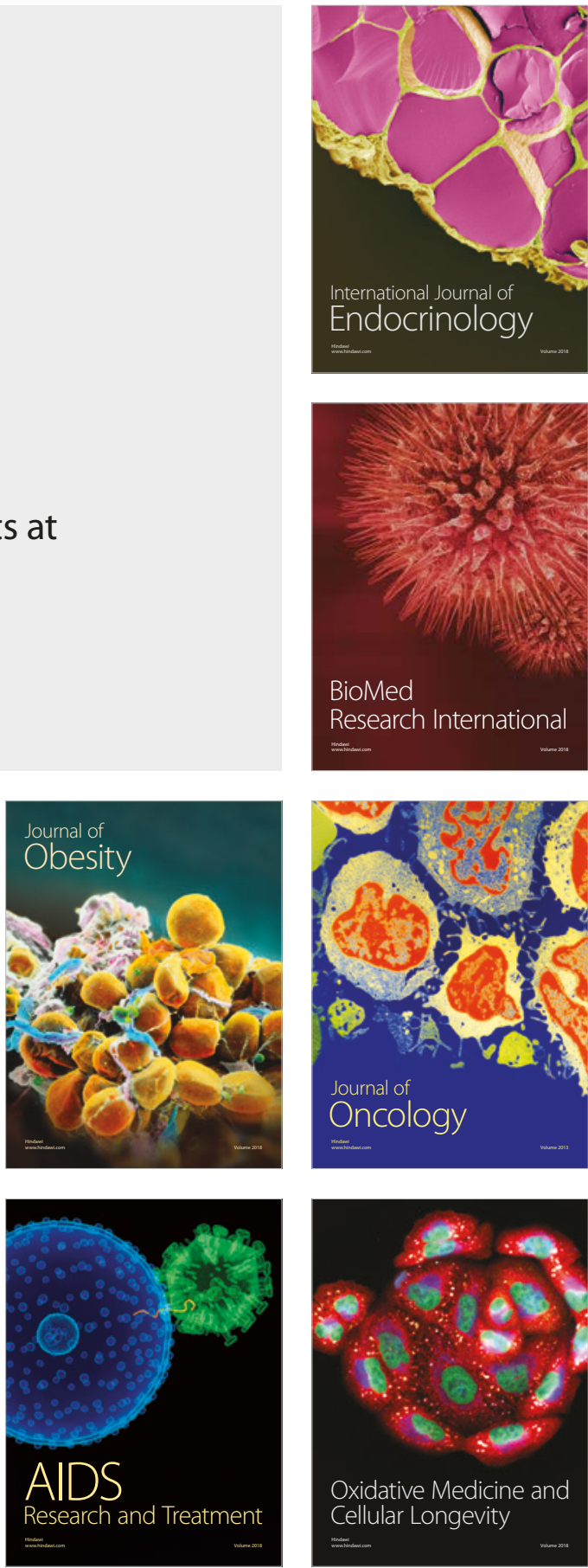